ISSN: 2162-3104 Print/ ISSN: 2166-3750 Online

Volume 8, Issue 2 (2018), pp. 1220-1255

(C) Journal of International Students

http://jistudents.org/

doi: $10.5281 /$ zenodo. 1250423

\title{
A Qualitative Phenomenological study of Emotional and Cultural Intelligence of International Students in the United States of America
}

\author{
Rohan Thompson \\ Huston-Tillotson University, USA
}

\begin{abstract}
This phenomenological study examined the role of emotional and cultural intelligence in the social integration of international students. The study included nine participants who were selected using purposeful sampling. The researcher used five main interview questions to guide the datacollection process. The questions were designed to help determine both whether the participant appeared to be competent in cultural and emotional intelligence, and how that competence then contributed to his or her social integration. The study findings revealed that emotional and cultural intelligence played an important role in enabling international students to integrate socially. This article seeks to offer a deeper understanding of the social integration challenges of international students, contribute to the existing knowledge, and offer suggestions for future research.
\end{abstract}

Keywords: cultural intelligence, emotional intelligence, international students, social integration

Peterson (2014) indicated that social integration into a different culture is very challenging, and requires emotional and cultural intelligence because it focuses on how individuals think and their ability to adapt. To integrate effectively, international students must not only understand but also interpret and respond to fellow students in a manner that positively affects them. For example, Wakeman (2009) explored emotional and cultural 
intelligence as a predictor of learning success or failure of international students. He believed that a person with a high emotional and cultural intelligence level should be more efficient at handling culturally diverse situations and better adapt socially to the change.

Habib, Johannesen, and Øgrim (2014) found that international students struggle most with social adaptation. Previous research has also shown that the academic performance of international students can be affected by factors such as cultural and emotional challenges. According to Li et al. (2010), "social integration into the university system, emotional support, and psychological health have all been identified to affect students' success in universities to some extent" (p. 3).

Previous research has shown that studying emotional intelligence will help one to understand the experiences of international students from a cognitive perspective. However, researchers have identified the importance of including cultural intelligence to understand further their social integration. For example, several researchers (Dusi, Messetti \& Steinbach, 2014; Huff, Song, \& Gresch, 2014: Malik, Cooper-Thomas, \& Zikic) linked emotional intelligence to native cultures but acknowledged the difficulties of using emotional intelligence in international settings. Petrides and Sevdalis (2010) also concluded that international students must be culturally intelligent to understand the differences that exist between their culture and that of the university in order to assist with the social integration process. Rienties, Héliot, and Jindal-Snape (2013) surveyed 191 international students and found that their home culture significantly affected the adaptability to the new culture.

The main focus of this study was to explore the role of cultural and emotional intelligence in the social integration of international students in American universities. The research questions were developed using the basic principles of phenomenological research noted by Moustakas (1994), who stated that research questions should "give a direction and focus on meaning, and in themes that sustain an inquiry, awakening further interest and concern, and account for our passionate involvement with whatever is being experienced" (p. 94). The research questions assumed two forms: a central question and three associated supporting questions.

- Question 1 (RQ1): How does emotional and cultural intelligence affect the social integration of international students in United States universities? 
- Supporting Research Question 1 (SRQ1): In what ways do international students employ emotional and cultural intelligences?

- Supporting Research Question 2 (SRQ2): How do international students' cultural beliefs affect the social integration process?

- Supporting Research Question 3 (SRQ3): How do international students experience social integration in American universities?

\section{LITERATURE REVIEW}

\section{Emotional Intelligence}

Emotional intelligence is understood as an essential component of human intelligence that, through innate abilities and acquired abilities, determines an optimum adaptation to the environment through an inspired management of emotions, feelings, and relationships with others (Niţă, 2014). The emotional intelligence of each international student can be affected by external factors such as cultural background and communication problems that can be caused by language barriers (Riggio, 2010).

In a previous study, Mohammad, Chai, Aun, and Migin (2014) concluded that emotional intelligence can significantly affect the stay of international visitors, because it can provide a more collaborative experience through better socialization. Emotional intelligence affects the personal thoughts and actions of individuals. Priya and Panchanatham (2014) stated that "it is a set of skills that not only leads to better academic and professional functioning but also good social interactions and healthy living, which result in personal satisfaction" (p. 2). With an increasing number of international students in American universities, there is a greater need to understand the social inabilities of these students (Kushner, 2010).

Emotional intelligence, although necessary in all aspects of life, is extremely vital to the educational environment because of the constant contact between students and teachers. For example, Wols, Schole, and Qualter (2015) argued that emotional intelligence is a needed component in the educational system. A teacher's interaction with international students severely affects their emotional intelligence. Studying teachers' levels of emotional intelligence, Gawali (2012) concluded that, because teachers are authority figures who interact extensively with students, their levels of 
emotional intelligence are also paramount. The researcher surveyed 413 teachers at multiple institutions of higher learning, and the results showed that teachers with high levels of emotional intelligence had better communication with students. The study also showed that these teachers with high levels of emotional intelligence had a positive impact on all students' emotional levels.

As human beings, individuals demonstrate many different emotions that are used to interpret subjective feelings that occur outside one's awareness (Wols, Schole \& Qualter, 2015). All human experiences are affected by emotions that act as the reasoning for the individual's behavior and thought process. Chaffey, Unsworth, and Fossy (2012) found that perception and insight were influenced by one's understanding of emotions. Human beings have 57 feelings, and a lack of emotional intelligence makes such feelings impossible to control (May \& Carter 2012). Therefore, international students who are emotionally intelligent are better able to adapt socially to those around them (Roy, Sinha \& Suman, 2013).

Verma and Dash (2014) argued that having a high-level of emotional intelligence leads to better social skills that can increase international students' ability to handle negative feelings. Sparkman (2009) concluded that international students have extremely diverse backgrounds and beliefs that make their social adaptation very complex. He surveyed 783 undergraduate students from universities across the United States; the results of his study indicated that emotional intelligence is a strong predictor of student success. Many of the international students entering the United States to attend college are older than American freshmen entering college (Verma and Dash, 2012), and, interestingly, Birknerová (2011) found that age was a factor for higher emotional intelligence in college students. The results of Birknerová's study were significant because they suggested that international students may have an increased chance of being socially adaptive.

\section{Emotional Intelligence Development}

Social integration is a critical factor in educational learning (Grant, Kinman, \& Alexander, 2014). Given that social integration is affected by the emotional intelligence level of the individual, developing and understanding emotional intelligence is vital to the learning success of international students. For example, Stark and Freishtat (2014) stated that social integration and emotional intelligence are highly interdependent. Coban, 
Karaddemir, Acak, and Devecioglu (2010), in a study in which they asked 144 international students to fill out a questionnaire on emotional intelligence, concluded that the development of emotional intelligence should be a part of the education process.

The broad scope of emotional intelligence theory is best identified by its widespread acceptance by researchers in different fields. According to Neophytou (2013), "the growing popularity and acceptance of Emotional Intelligence indicate that it is something that modern society values" (p. 145). Emotional intelligence is associated with learning, and previous studies have linked emotional intelligence to higher education. For example, Bazerman (2015) stated that moving from one country to another, international students experience the process of self-development in the social context to assist with academic success. Priya and Panchanatham, (2014) stated that "our emotional intelligence is of utmost importance in individual's life" (p. 1). Coover and Murphy (2010) further concluded that the stronger the elements of emotional intelligence, the more academically successful the student tends to be.

Yang, Yeh, and Wong (2010) argued that "meaningful learning and individual development were achieved through social interaction" (p. 287). Every theory of social interaction seeks to identify patterns and behaviors that can be measured to identify traits and characteristics (Priya \& Panchanatham, 2014). Patterns were critical for this study because, as international students were being considered, formulating trends could identify possible problems in social interaction. Several studies have identified the social challenges of immigrants in general (Chen, Hicks \& While, 2014; Sandhu, and Asrabadi, 1994; Wang, Puri, Slaney, Methikalam, \& Chadha, 2011). Testing and research have led to the conclusion that the theory of emotional intelligence does exist in many different facets of life and in areas of study such as social challenges caused by emotions (Grant, Kinman, \& Alexander, 2014; Holinka, 2015). According to Priya and Panchanatham (2014), "all aspects of human livelihood are affected by emotions" (p. 1). Researchers have studied for years what drives human behaviors and actions that affect life as students, professionals, employees, and leaders. Nadeem and Haider (2014) stated that "emotional intelligence allows the individual to judge adequately other's state of mind" (p. 2).

Alsmadi and Alsmadi (2009) indicated that "it is critical that test developers and users strive to ensure the validity of their tests and instruments for the target population and purposes for which they were 
designed" (p. 284). The theory of emotional intelligence has been applied to many social and psychological studies such as the one by Salovey and Mayer (1990), who theorized that the emotional and social intelligence of a person is just as important as IQ in determining the success of an individual. According to Pope et al. (2012), "studies have also considered the effects of emotional intelligence on the academic and social integration of undergraduate students" (p. 908). Mohammad et al. (2014) stated that "emotional intelligence within a business, or organization, can assist in reducing employee turnover, identifying transformational leaders, improving organizational culture, stimulating creativity, and enhancing employee acceptance of radical change" (p. 212).

\section{Cultural Intelligence}

According to Earley and Ang (2003), individuals can only be considered culturally intelligent when the four factors are all engaged and working. All four factors can be improved over time and allow an individual who is not culturally intelligent to be in that state once the factors are addressed. Groves and Feyerherm (2011) argued that cultural intelligence is a better tool for analyzing judgment than emotional intelligence and other characteristics. Further research by Groves and Feyerherm found that those with higher levels of cultural intelligence were better able to adapt to a changing environment.

Previous research has concluded that cross-cultural interactions can be enhanced through an understanding of cultural differences (Rockstuhl, Hong, Ng, Ang, \& Chiu, 2010). Previous research has also indicated that cultural intelligence is not widely used in the realm of higher education (Ronen \& Shenkar, 2013). However, the basics and traits of cultural intelligence can be applied in multiple settings such as higher education (Groves \& Feyerherm, 2011). The fundamentals of the theory of cultural intelligence apply to higher education because of its diverse setting (Petrovic, 2011). MacNab, Brislin, and Worthley (2012) collected data from 370 participants in higher education in Australia and the United States and concluded that improving cultural intelligence could be very difficult because of vast differenceses that exist among countries, but if done correctly can have an effect on the students' ability to learn continually.

Franklin-Craft (2010) also conducted one of the few studies applying cultural intelligence to the environment of higher education. $\mathrm{He}$ surveyed 465 students and concluded that international travel and 
communication about cultural diversity with other individuals contributes to higher levels of cultural intelligence. Cultural intelligence is a construct that can be improved over time. Ahn and Ettner (2013) conducted research focused on international graduate students in the United States. They found that international students understood the importance of cultural intelligence in a global environment, even though many had little culturally specific knowledge.

$\mathrm{Ng}$ and Earley (2006) argued that cultural intelligence is the ability to understand and adapt to new and different cultures. Researchers of cultural intelligence seek to understand why some people adapt more readily to cultural settings. Yip (2014) found that 50\% of international students who had mentors were better able to adjust to the change in culture. Crosscultural problems are a common occurrence when dealing with people from contrasting areas and backgrounds. Arasaratnam and Doerfel (2005) stated, "Intercultural communication has been defined beyond strictly nationality differences to include differences in beliefs and ethnicities" (p. 145).

Cultural adaptability requires a mindset that allows for interaction in various cultural contexts (Ramsey, Barakat, \& Aad, 2014). Understanding the culture of American universities will require international students to have open minds. Cultural intelligence generates a level of confidence that enables individuals to handle diverse cultural situations (Diao \& Park, 2012). In previous research, Kim and Van Dyne (2012) concluded that predictors of cultural intelligence are very scarce, but what does exist is more than sufficient such as prior intercultural contact and self-observation. Many times the root of all cross-cultural problems is a lack of understanding among all involved (Ramsey et al., 2014), and because emotions usually dictate how people react to the unknown, it is paramount to disregard any preconceived notions (Yip, 2014). According to Immordino-Yang (2009), the cultural experiences learned help develop an individual's emotions that can sometimes be negative, which makes controlling them paramount to intercultural growth.

\section{Cultural Intelligence Development}

Cultural intelligence can be increased over time with studying abroad (Gupta, Singh, Jandhyala, \& Bhatt, 2013). The more individuals are entrenched in diverse cultures, the better chance of their having an appreciation for beliefs other than their own (Gupta et al., 2013). The theory of cultural intelligence addresses issues related to culture by focusing on the 
individual characteristics and personality traits of a person rather than merely the beliefs and norms associated with the culture (Ang et al., 2007). The addition of cultural intelligence within any study is important because it allows each participant to provide an individual account of his or her cultural experiences (Van Dyne et al., 2012).

Earley and Ang (2003) stated that a culturally intelligent person "must create a new mental framework for understanding what is experienced and witnessed" (p. 61). Culturally intelligent individuals have the capability to react appropriately to new cultural situations. Wagner (2008) stated, "Corporations need young people who work effectively with others and understand and respect differences - not just in our country but around the world" (p. 28). The model of cultural intelligence by Earley and Ang (2003) is significant to the study because it examines culture in a holistic manner.

Ang, Van Dyne, and Tan (2011) conducted an extensive study on the value of cultural intelligence and concluded that, as a construct, cultural intelligence is very meaningful and presents clear and precise developments of intelligence. They also found that cultural intelligence had predictive validity in indicating relationships between cultural effectiveness and cultural intelligence. Cultural intelligence is a relatively new construct, but according to Engle and Crowne (2010), research has shown positive results regarding the link between successful leadership and high cultural intelligence.

The ability to interact effectively with other cultures is a necessary skill for any individual associated with globalization (Rockstuhl, Seiler, Ang, Van Dyne, \& Annen, 2011). With the importance of cultural intelligence documented, researchers are extensively trying to understand why some people are better able to communicate with individuals from other cultures. Cultural intelligence extends beyond understanding other cultures and pushes individuals and leaders who are dealing with foreign groups to act appropriately (Thomas, 2005). For international students, the adaptation to the American culture can be easier to accomplish with the assistance of those who already understand the beliefs and norms of the culture (Yu et al., 2014).

Cultural intelligence provides the tools needed to develop an environment where responding to the words and actions of people can be done more efficiently (Earley, 2002). Peterson (2014) further stressed the importance of cultural intelligence, noting that cultural intelligence features 
a set of behaviors that are needed to interact with people of other cultures. To be culturally intelligent, one needs to understand not only the culture of an individual but also the situation that surrounds it (Rockstuhl et al., 2011). Peterson (2014) interviewed 75 international students from six of the largest universities in the United States. The interviews from the participants elicited their opinions on what they believed was necessary for international students to be successful. He concluded that the best way for international students to adapt globally is to practice cross-cultural simulations.

Earley, Ang, and Tan (2006) stated that "individuals with high cultural intelligence have a strong mastery and a sense of emotional display and physical presence" (p. 34). Individuals with high cultural intelligence usually show all four of its components: motivation, cognition, metacognition, and behavior (Ang, Van Dyne, Koh, \& Ng, 2004). Human capital is an asset that is hard to replace, and extensive research has been conducted on the impact of culture on performance (Jyoti \& Kour, 2015).

\section{International Students and Social Integration}

In a report by the U.S. Department of Commerce, international students contribute more than $\$ 27$ billion to the US economy (Institute of International Education [IEE], 2014). In addition to the financial contributions they present, the academic performance is essential to the overall prestige of the university. According to Li, Chen, \& Duanmu (2010), “international students' distinct demand from home students for various courses such as Mathematics and Engineering, helps the receiving universities to maintain a diverse range of subjects" (p. 2). The international student population in the United States grew by $8.1 \%$ from 2002 to 2014, and analysts expect this figure to continue to trend upwards over the next decade (IEE, 2014). Also, it is estimated that the presence of international students provides jobs for more than 270,000 individuals a year (IIE, 2014).

Research has concluded that emotional intelligence is important for international students because it can assist with the adaptation of cultural awareness that in turn can lead to better social integration. For example, Pope, Roper, and Qualter (2012) stated that emotional intelligence can influence the social integration of international students. Furthermore, Hughes and Schlosser (2014) argued that the brain gathers emotions that are used to assist the cognitive process of individuals and respond to complex situations. Immordino-Yang (2009) further stated that emotion and learning are never separated but rather depend highly on each other. 
Lam and O'Higgins (2012) argued that the major advantage for domestic students as compared to international students is that domestic students are well aware of the surroundings and the need to learn continually is nonexistent. According to Lam and O'Higgins, this disadvantage means that international students must have a higher level of emotional and cultural intelligence than their counterparts. Studies have shown that social integration generates a standard of comfort for international students that create an environment where they can concentrate on classwork and receive better grades. For example, Rienties, Beausaert, Grohnert, Niemantsverdriet, and Kommers (2012) found that a compensatory relationship exists between social adjustment and study performance.

\section{RESEARCH METHOD}

\section{Qualitative}

The qualitative research method was chosen for the study because of its fundamental nature, which allows the researcher to have a better understanding of the participants in the study (Lodico, Spaulding, \& Voegtle, 2010; Rumrill, Cook, \& Wiley, 2011; Yin, 2009). Merriam (2009) stated, "Qualitative researchers are interested in understanding the meaning people have constructed, that is, how people make sense of their world and the experiences they have in the world" (p. 13). In relation to this study, a qualitative research method provided answers as to how the social integration of international students is affected by emotional and cultural intelligence.

According to Creswell (2013), qualitative research is "an inquiry process of understanding based on a distinct methodological tradition of inquiry that explores a social or human problem" (p. 249). Using a qualitative method, the researcher was able to provide a holistic picture and study the phenomenon within the natural environment of the study (Creswell, 2013). The expectation was that each participant would provide information that was unique to his or her experiences but, more importantly, that exposed the beliefs and norms that were essential to his or her culture.

Qualitative research methods allow a researcher to build a complete picture, analyze words and experiences, report the participants' views in detail, and provide a natural setting in which a study takes place (Creswell, 2013). Also, a qualitative method places emphasis on themes instead of concentrating on statistical information (Turner, 2010). There are many 
approaches to qualitative research, but the specific approach chosen for this study was phenomenology. Phenomenology is a popular approach in qualitative research because it provides detailed, first-hand information of individual's experiences (Nichols, Kotchick, McNamara-Barry, \& Hasking, 2010).

\section{Phenomenology}

This approach was chosen because it allowed the participants within the study to give meaning to their experiences as related to emotional and cultural intelligence. Creswell (2013) stated that the "phenomenological study describes common meaning for several individuals of their lived experiences of a concept or phenomenon" (p. 76). This approach allowed participants not only to tell a story about their experiences in the American universities but also to provide a background of the cultural beliefs and norms that contributed to their emotional and cultural intelligence.

Moustakas (1994) stated that, in phenomenological studies, texts are analyzed with a primary focus "to provide a description of the lived experience from the participant's perspective" (p. 809). This information then can be used to identify any similarities or differences that may exist. Phenomenology is an approach used to explore and examine perceptions that individuals assign to their experiences (Creswell, 2013; Nichols et al., 2010). In this study, the researcher wanted to explore the social integration of international students, which made phenomenology an appropriate method because it captured the emotions of each individual (Finlay, 2013).

Specifically, the researcher applied a phenomenological approach based on the principles of transcendental phenomenology. This particular approach to phenomenology began in the early twentieth century by Edmund Husserl (1970). In his book, The Crisis of European Sciences and Transcendental Phenomenology, Husserl criticized the natural sciences and provided a strong argument for philosophy as a rigorous science that maintains the identity of the individuals. Husserl used transcendental idealism to explain how phenomenological assertions can be justified as a research method.

Moustakas (1994) defined transcendental phenomenology as "a scientific study of the appearance of things, of phenomena just as we see them and as they appear to us in consciousness" (p. 94). Transcendental phenomenology was appropriate for the study because it took the focus off the researcher, placing it instead on the reflections of the participants. The 
researcher attempted to set aside his own experiences by focusing on the experiences and perspectives of the participants in the study. Phenomenological research focuses on a phenomenon and its particular, unique appearances (Gallagher \& Zahavi, 2012).

Moustakas (1994) provided systematic procedures for using transcendental phenomenology as a research method. The procedures provided by Moustakas make this approach appealing for less-experienced researchers. Patton (2002) argued that researchers should never have predetermined restrictions on the findings; rather, researchers should be open to whatever information presents itself. The rationale for selecting transcendental phenomenological design was that it would help answer the research questions by allowing the researcher to document, through interviews, the in-depth details of the emotional and cultural intelligence of international students.

\section{Participants}

The population of interest was international students who entered the country with the primary purpose of attending and graduating from American universities. The intent of the study was to explore the role of cultural and emotional intelligence in the social integration of international students in the American universities. The population was selected for the research because it provided a diverse group of individuals who had varying views of the world. Although the population of the study was limited to international students, it was an appropriate group based on the research topic.

The study participants were obtained from a southern private university. According to the director of admissions, at the time of the study, the university had 39 international students from 13 different countries on its main campus. Of the 39 international students, 26 were classified as juniors or seniors. The participants within the study were juniors or seniors who had been at the university for at least 2 years. This criterion ensured that all participants had the necessary experience to give a valid account of their cultural experience. The study used purposeful sampling to limit to a small number of potential participants (Salkind, 2008). More specifically, criterion sampling was utilized in the study because the researcher was more concerned with identifying patterns (Creswell, 2013).

The study sample was anticipated to be $8-12$ participants, which is within the recommended size range for a phenomenological study 
(Creswell, 2013). The sample size was selected to enhance the validity of the study. According to Englander (2012), when selecting a sample size, the researcher must ensure that the participants have the experience needed to answer the research questions. The sample size selected was in agreement with Creswell (2013), who indicated that this research method should have a sample size between 5 and 25 individuals who are directly related to the phenomenon being considered.

Before any interview was conducted, each participant was provided a consent form (Appendix A) that detailed the purpose of the study and must be signed. Interviews were the only data collection method used in the study. The interview questions (Appendix B) were well organized and presented in a logical manner based on the four research questions of the study. The participants were advised that the researcher would be the instrument used to conduct the interviews. All data were to be audiorecorded for later transcription and were to be collected through conversational, face-to-face interviews.

It was imperative that each interview was approached with an open mind and fresh perspective. According to Moustakas (1994), researchers call this epoche attitude, and this was incorporated throughout the data collection process to guarantee all information was collected in a nonjudgmental manner. Moustakas also stated that setting aside prejudgments is essential to transcendental phenomenology because it forces the researcher to view the information for the first time and in its totality. Also, bracketing, which is a means of validating the data collection by setting aside previous experiences and beliefs, was to be incorporated. This would ensure that only the participants' experiences were evident in the research.

The participants answered open-ended, conversational questions regarding emotional and cultural intelligence and the social integration process into the university. The researcher ensured that all interview questions were worded appropriately to avoid any misunderstandings. The interview questions were developed with the intention of obtaining in-depth information to answer the primary research question and the supporting questions. The exact data collection procedure consisted of

- obtaining permission to conduct the study;

- sending all consent forms to potential participants;

- scheduling all face-to-face conversational interviews;

- conducting interviews;

- transcribing interviews; and 
- analyzing collected data.

The researcher expected the interview questions to be answered in a reasonable timeframe. The predetermined amount of time for each interview was 60 minutes. The amount of time chosen seemed adequate, as it would allow the researcher and the participant to become comfortable with each other and obtain the necessary information. Also, the amount of time would allow for an interview that was well-paced for all questions and answers. In addition to recording all interviews, the researcher also took notes to capture the body language and voice description of each participant depending on the method used to conduct the interview.

Upon receiving approval from the Institutional Review Board on May 19, 2016 (Appendix C), the researcher began soliciting a purposeful sample of 8-12 potential participants who met the criteria of the targeted population. A purposeful sampling method was used to limit potential participants to a small number who could "purposely" provide an understanding of the cultural differences between their home country and the United States (Salkind, 2008). The candidates' names and contact information were obtained from the admissions director.

The data for this study were collected from interview questions using the critical incident technique. Twelve potential candidates were sent an email with the introductory letter. Twelve candidates responded, but all were skeptical about the interview process and wanted more information. After 3 days, the researcher contacted the 12 potential participants by telephone and further explained the purpose of the study. Ten of the candidates agreed to participate in the study. The ten candidates who agreed to participate in the study were from different countries. The participants were then emailed the consent forms, all of which were returned prior to the interviews. The sample size was originally set at 8-12 participants; however, saturation was met at 9 participants, and, therefore, the study was concluded after nine interviews.

The researcher conducted face-to-face interviews with the participants between May 25, 2016, and June 06, 2016. The interviews took place in a private office reserved for board meetings by the university. Each participant was given a copy of the interview questions prior to the interview. The data were derived from one-on-one, open-ended questions that followed the critical-incident format. Utilizing this method allowed the researcher to obtain in-depth, firsthand information and to observe body language and facial expressions of the participants. The interviews provided 
data necessary to answer the research questions. All responses were recorded, and notes were taken during the interview.

\section{Interview Questions}

A total of nine participants were interviewed for this study. Each participant was asked five main questions to help them tell their story, and each main question was supported by probing questions to help along the way. The interview began with a brief description of the study and the researcher sharing his own experiences as an international student relative to the adjustment process from his home culture to that of the university. This approach was chosen in order hopefully to help with camaraderie and with the participant being able to remember his or her own experiences easily. Then the following questions were asked to guide the interview:

\section{Major Question 1}

Can you tell me a few stories about your adjustment to the culturally different context of the United States and, in particular, the university?

\section{Supportive Questions to 1:}

- One of the stories you mentioned was . I would like to ask you some questions about that story.

- How did you get involved in that situation?

- How did that particular situation make you feel?

- How did you react to the situation?

- Was the situation resolved? If not, how does that make you feel? If yes, how did it make you feel?

- Has that situation changed you in any way?

- How has it helped you to adjust to life in the United States and on campus?

\section{Major Question 2}

How is your relationship different with students from your own country versus other international students and American students?

\section{Supportive Questions to 2:}

- What do you believe is the reason for the difference in relationships?

- How do you think the differences can be resolved? 
- How do the differences in relationships make you feel?

- Have the differences changed you in any way?

- How have the differences affected your adjustment to life on campus?

\section{Major Question 3}

Can you tell me a few examples during your time on campus that the resources or lack of resources available helped or hurt with adjusting to American culture?

\section{Supportive questions to 3}

One of the examples you mentioned was . I would like to ask you some questions about that example.

- How did that particular situation make you feel?

- How did you react to that situation?

- Who was involved in that situation?

- How would the situation be handled differently if you were back in your home country?

\section{Major Question 4}

Can you tell me something that happened to you on campus that was negative?

\section{Supportive Questions to 4:}

- What happened in that situation?

- Who was involved in the situation?

- How did it make you feel?

- How did you react to the situation?

- Was the situation resolved? If not, how does that make you feel? If so, how does that make you feel?

- How has it affected your view of the people involved and the campus in general?

\section{Major Question 5}

Can you tell me an example of how you are different in your junior/senior year socially compared to your freshman and sophomore year? 


\section{Supportive Questions to 5:}

- What has happened to cause this change?

- Who was involved in this change?

- How are your feelings now that the change was made?

Table 4.1. Demographics of Participants

\begin{tabular}{|c|c|c|c|c|}
\hline Participant & Gender & $\begin{array}{l}\text { Country of } \\
\text { Birth }\end{array}$ & $\begin{array}{l}\text { Number of } \\
\text { Years in the } \\
\text { United } \\
\text { States }\end{array}$ & $\begin{array}{l}\text { Academic } \\
\text { Status } \\
\end{array}$ \\
\hline 1 & Female & Columbia & 4 & Senior \\
\hline 2 & Female & Jamaica & 3 & Junior \\
\hline 3 & Male & Ukraine & 3.5 & Junior \\
\hline 4 & Male & India & 4 & Senior \\
\hline 5 & Male & Germany & 3 & Junior \\
\hline 6 & Female & Japan & 3 & Junior \\
\hline 7 & Male & Bahamas & 2.5 & Junior \\
\hline 8 & Male & Dubai & 4 & Senior \\
\hline 9 & Female & Kenya & 3 & Junior \\
\hline
\end{tabular}

\section{RESULTS}

Four females and five males participated in the study. The study participants had varying backgrounds and had experienced the American culture. The researcher asked each participant four questions about his or her demographics before beginning the interview questions. Two demographic questions collected information relevant to the criteria established to be part of the study, and two questions collected information about the participants' time to learn and adjust to the culture of the United States and the university campus. Because time could influence an individual's cultural awareness and thus influence one's social integration, this demographic information was important to the study. Prior research by Pope et al. (2012) showed that time in a country could affect international student's social integration. The demographic information included gender of participant, time in the United States, academic status, and country of birth. Table 4.1 shows the information collected from the demographic questions. 
Gender of the participants was important to show inclusiveness of the study. Having both male and female participants provided validity to the study through diversity. The distribution of participants by gender was five (56\%) male and four (44\%) were females.

Figure 4 shows the academic status of the participants. This is a very important criterion of the population sample because academic status can be closely linked to time within the culture or university. Additional time spent at the university would increase the chances of a participant's being aware of and using the available resources. The distribution of participants by gender was six (66.6\%) juniors and three (33.3\%) seniors.

\section{Emerging Themes}

The researcher used five main interview questions to guide the datacollection process. Each main question was supported by probing questions to help the participants tell their stories. The questions were designed to help determine both whether the participant appeared to be competent in cultural and emotional intelligence, and how that competence then contributed to his or her social integration. The interview questioning generated six themes.

\section{Theme 1: Lack Cultural Awareness}

As indicated in Table 4.2, three invariant constituents and 49 references supported the theme that American students lack cultural awareness. Participant 1 explained,

The reason for the difference in relationships between international and American students is the lack of cultural understanding by American students. I find that international students have better relationships with other international students. We understand international students because of travel and cultural experience but American students know little about the world and live in a bubble.

During her freshman year, Participant 2 struggled emotionally with frequent interruptions in the classroom by American students to questions directed at her from the professor. She shared her frustrations:

I hate when I'm in the classroom and American students talk over me when the professor asks a question directed at me. If the professor asks me a question, I think that he or she is 
looking for me to give an answer. It shows a lack of respect for us international students because I have talked to several others who said they have experienced the same thing in the classroom.

Participant 6 expressed feelings of being stereotyped. She recalled, "I remember my friend when introducing me to high school students, used her hands to pull her eyes back to signify that I was Japanese. I thought that was kind of stereotyping and even discrimination." Participant 8 recalled that, in spite of his attempts fit into the culture of the university, he always sensed that he was looked at as an outsider. He expressed that the differences in relationships between international and American students cannot be resolved because American students believe international students are intruders. He said,

The differences cannot easily be solved because it's a territorial thing. Imagine I come to your house and act like I belong there and am in some ways superior to you; it would not make you happy. Well, the same applies for many American students who see us as intruders who want to take their territory. I'm not saying that is true for all American students, but that it is personal belief.

Table 4.2. Theme 1: Lack of Cultural Awareness

\begin{tabular}{lcc}
\hline Invariant Constituents & $\begin{array}{c}\text { Number of } \\
\text { Participants }\end{array}$ & $\begin{array}{c}\text { Number of } \\
\text { References }\end{array}$ \\
\hline Lack of adjustment to culture & 9 & 20 \\
Negative feelings & 8 & 27 \\
No change in cultural belief & 3 & 6 \\
\hline
\end{tabular}

The entire sample of participants (100\%) believed that Americans lack cultural awareness and that this affected their social integration. A total of $100 \%$ of the sample participants believed that Americans do not understand other cultures and the same percentage (100\%) acknowledged that they had a better relationship with international students rather than American students. Forty-four percent of the participants shared personal experiences of negative stereotyping by Americans. 


\section{Theme 2: Social Adjustment Problems}

As indicated in Table 4.3, three invariant constituents and 53 references supported the theme that international students had problems adjusting socially to the culture of the campus and of America in general. Participant 2 believed that the cultural differences were "much more than anticipated but one in particular stood out to me." She said, "The biggest cultural difference is the food in the cafeteria. The food provided is not very healthy, and although many international students, including myself, have complained, it remains the same." She added,

All you can do is go to your room and find something else to eat. It's very frustrating and shows that the administration does not value our opinions. We are spending money that we shouldn't have to spend because we are paying a lot of money to the university and the cafeteria.

Participant 6 explained that in the Asian culture, hugging is a rare occurrence but is done as a greeting here in America. She explained the difficulties of adjusting to that cultural change. She noted,

It was very awkward for me. I felt very uncomfortable to the point where it I would feel violated when someone hugged me. I prefer to bow because I don't think you need a physical connection to simply say hi. I don't know if I would ever get used to it.

Participant 8 recalled feeling very nervous around American students because it seemed they were looking at him with judgment because he dressed differently than they. He stated,

In the part of India that I am from, we cover our skins-even the men. So when I got here, people were staring at me and I even heard whispers of people stating that I am Muslim and they need to watch me.

When asked how this negative attention made him feel, he responded,

It bothers me. It bothers me because Americans talk about peace and respect but many Americans show a difference. I am not judging all American because as I said earlier, we are all different people but I have been around many that have 
demonstrated that behavior. It is very sad and discomforting that in 2016, people still think this way.

Participant 4 believed that all individuals are different, and he came to college to get an education, not to change his cultural beliefs. He recalled a situation on campus when a young lady committed suicide, and everyone on campus was mourning and sad. He stated,

The situation was sad, and when my friends would talk about it, I would withdraw myself from the conversation because I had mixed feelings. On one hand, it was sad that a human being was gone, but suicide is the easy way out and, in my culture, we don't feel sad for people who commit that act. It's my belief that those people don't deserve any sympathy and I don't think I would ever change that feeling.

Table 4.3. Theme 2: Social Adjustment Problems

\begin{tabular}{lcc}
\hline Invariant Constituents & $\begin{array}{c}\text { Number of } \\
\text { Participants }\end{array}$ & $\begin{array}{c}\text { Number of } \\
\text { References }\end{array}$ \\
\hline Lack of adjustment to culture & 9 & 20 \\
Negative feelings & 8 & 27 \\
No change in cultural belief & 3 & 6 \\
\hline
\end{tabular}

Nine participants ( $100 \%$ of the sample) acknowledged that, during their years in college, they had experienced some form of social adjustment problems. All nine participants thought that, as they overcame the social issues, they were better able to integrate socially into the university. Nine $(100 \%)$ of the participants expressed an initial lack of adjustment to the American and the university cultures. Eight $(88 \%)$ of the nine participants indicated that, at some point in their journey, they experienced negative feelings that affected how they viewed people on campus. Three participants said that, even though they were able to resolve the social adjustment problems, such resolution created no change in their cultural beliefs.

\section{Theme 3: The Cultural Mindset}

As indicated in Table 4.4, three invariant constituents and 32 references supported the theme that cultural differences affected the social integration of international students. Participants 1, 2, 4, 6, 7, 8, and 9 all 
referenced food as a major adjustment that affected them socially. Participant 1 explained,

There were so many cultural differences that it would be hard to name just one or two that affected me socially. However, I would say the food was a big adjustment for me and because I was not eating as I normally would, it made me very moody.

Participant 2 said, "The food made it very difficult for me to adjust socially because it made me angry." Participant 4 elaborated, noting that "the food also was very different; it took me a very long time to get used to eating American food, and when I did, I noticed a change in my attitude." Participant 9 commented,

When I came to America, I did not know what to expect. I had little knowledge of the country and especially [of] the food. I have been here for 3 years and I am still struggling with the food. It's hard to be social when you are hungry.

Although struggling with some components of the culture, participants also indicated a willingness to learn the American culture. Participant 5 stated,

You can have all the programs and resources in the world, but that person must be willing to step out of their comfort zone. I was always willing to learn the American culture but not so acceptable to changing to the culture.

Participant 5 further emphasized this point by suggesting,

As international students we are willing to learn the culture, but that does not mean we have to adopt the cultural beliefs and norms. I have learned many things about the American culture, but that does not mean I agree with them all.

Beyond being willing to learn the American culture, international students expressed openness to such learning. Participant 9 said, When I left Kenya, I was open to learning the norms and beliefs of Americans. However, I think I became more fascinated with the norms and beliefs of other international students. They seem more knowledgeable about their culture than American students.

Participant 4 shared his conviction that, in his research prior to coming to America, he realized that Americans were very individualistic, which is different from the Indian culture that is more communal-but that 
was exciting to him. He said, "I took the cultural difference as an opportunity to learn something new. In some ways I felt socially awkward, because I really did not fit in but I was open to any possibility."

Table 4.4. Theme 3: The Cultural Mindset

\begin{tabular}{lcc}
\hline Invariant Constituents & $\begin{array}{c}\text { Number of } \\
\text { Participants }\end{array}$ & $\begin{array}{c}\text { Number of } \\
\text { References }\end{array}$ \\
\hline Cultural differences & 9 & 19 \\
Willingness to learn American culture & 4 & 7 \\
Open to learning new culture & 4 & 6 \\
\hline
\end{tabular}

The notion that many cultural differences affected social integration into the university was supported by $100 \%$ of the sample of participants. The entire sample $(100 \%)$ thought that there were too many cultural differences that affected their social integration to simply name a few. The study results also indicated that $44 \%$ of the participants were willing to learn the American culture but were skeptical about adapting to it and the same percentage (44\%) were open to learning a new culture and willing to adapt to the beliefs and norms if it would help them socially integrate into the university.

\section{Theme 4: Improvement in Social Integration}

As indicated in Table 4.5, four invariant constituents and 53 references supported the theme of improvement in social integration. Participant 1 credited his ability to communicate better with American students to "taking the time to understand the norms and beliefs of the American people." She continued, "I feel great. I will always be a Columbian and keep my beliefs, but now I have a greater appreciation for American culture, and it has created a sense of confidence in me when communicating with American students."

Participant 3 recalled,

When I was a freshman and sophomore and I was not in a good mood, it was a little frustrating when people would be nice to me. Especially when I was homesick and wanted to go home, I would be thinking to myself why are these people talking to me. But when I became a junior, I think I realized that they were just trying to make me feel welcome. 
He shared his observation that "Ukrainians are not the nicest people, but now I am nice to everyone, and my friends see the change in me when I go back home."

Participant 9 said, "So I would say my relationship was an evolving process with American students. I think at first it was easier to be with other international students, but as time passed it became just as easy to be around American students." She noted,

For the most part I try to keep an open mind. I eventually realized that it was just me being emotional about cultural differences because American students simply do not understand international students because they did not have the same experiences. You can't blame them for not having those experiences. said,

Participant 8 , reflecting on his social behavior through the years

Well my first year, my English was not very good. I could listen to people but it was hard for me to communicate with them. That made a big difference in my social behavior. It's hard to be socially active if you can't communicate with the person. And my second year, my English was a lot better and by the time I reached my junior year I was able to fully communicate with everyone.

Table 4.5. Theme 4: Improvement in Social Integration

\begin{tabular}{lcc}
\hline Invariant Constituents & $\begin{array}{c}\text { Number of } \\
\text { Participants }\end{array}$ & $\begin{array}{c}\text { Number of } \\
\text { References }\end{array}$ \\
\hline Better understanding of American culture & 7 & 16 \\
Positive feeling & 7 & 10 \\
Adapting to new environment & 6 & 16 \\
Change in social behavior & 6 & 11 \\
\hline
\end{tabular}

The social integration theme captured the participants' recollections of experiences that described an improvement in their socialization from their arrival at the university to their junior and senior years. The experiences included (a) gaining a better understanding of the American culture, (b) experiencing positive feelings, (c) adapting to the new 
environment, and (d) acknowledging a change in social behavior. Of the sample, nine participants $(100 \%)$ recalled positive changes in their social integration as a junior or senior. Seven of the participants $(77 \%)$ had a better understanding of the American cultural beliefs and experienced positive feelings, while $(66 \%)$ of the sample adapted to the environment and had a change in their social behavior.

\section{Theme 5: Importance of Resources}

Participant 5 recalled,

When I was a freshman, I was very shy, especially around people. But back home in my normal environment, I am not a shy person. But dealing with language barriers and homesickness, I was really shy, and I kept to myself. When I became a junior, that shyness went away because my English was much better and I could have conversations with everyone.

As indicated in Table 4.6, two invariant constituents and 19 references supported the theme of resources being available as a very important prerequisite to the social integration of international students. Participant 3 shared his position relative to the resources available to international students:

I thought the university provided many opportunities to adjust to the culture. We had movie nights and many other things around campus that brought people together. The professors were really nice and encouraging and that really helped the adjustment in the classroom. We had an international house on campus where we could go and hang out with other international students.

5 stated,

Describing his understanding of the American traditions, Participant

I have [a] couple [of] friends that studied in the United States, and they told me it's a great opportunity to obtain a great education and experience a new culture. So I took my necessary test and applied to the university. I was accepted, and I spent the next month learning as much as I could about the American people and some of things that they celebrate like July 4th and Memorial Day. 
Participant 4 also believed he was ready for the opportunity to study in the United States. He stated,

I knew it would take me time to understand the American culture and to get to know the people. I think I studied the norms of Texans for over 2 months because I wanted to fit in. I knew that Texans like guns and football.

Participant 8 expressed his awareness of the resources available to international students but thought the process of implementing them could be improved. He said,

I believe the university does an excellent job of providing ways of getting international and American students together. We have many activities around campus that help with us coming together. But, if we are going to be together, then it is important that you know about my beliefs so we can communicate effectively. What is the point of the university creating resources that bring us together if we cannot talk to each other when we are together?

Table 4.6. Theme 5: Importance of Resources

\begin{tabular}{lcc}
\hline Invariant Constituents & $\begin{array}{c}\text { Number of } \\
\text { Participants }\end{array}$ & $\begin{array}{c}\text { Number of } \\
\text { References }\end{array}$ \\
\hline Awareness of resources & 9 & 9 \\
Awareness of traditions & 6 & 10 \\
\hline
\end{tabular}

All of the participants (100\%) acknowledged that, although the university was limited in resources, those available were very important to their social integration. Of the nine participants, all (100\%) acknowledged that the small size of the university made it relatively easy to be aware of the available resources. However, they also acknowledged that the small size of the university may have affected their social integration because of lack of activities. All of the participants (100\%) expressed gratitude to university officials for arranging visits to different places around the country and involving them in special celebrations because such opportunities assisted in their social integration. Of the nine participants, six (66\%) acknowledged that they were aware of the national traditions of the American culture such as holidays, celebrations, monuments, and special places of interest. 


\section{Theme 6: Acceptance of Cultural Differences}

As indicated in Table 4.7, three invariant constituents and 20 references supported the theme that international students accepted the cultural differences as they became juniors and seniors. Participant 3 acknowledged that her cultural perspective had not changed. She provided insights that

"the culture has not changed me because I am who I am. Just as how I had to accept Americans for who they are, they should have to accept me for who I am. I did not come over here to fit in but to get an education."

Table 4.7. Theme 6: Acceptance of Cultural Differences

\begin{tabular}{lcc}
\hline Invariant Constituents & $\begin{array}{c}\text { Number of } \\
\text { Participants }\end{array}$ & $\begin{array}{c}\text { Number of } \\
\text { References }\end{array}$ \\
\hline Resolve situations & 7 & 11 \\
Understand the environment & 3 & 4 \\
People are different & 3 & 5 \\
\hline
\end{tabular}

She further noted that "any issues I have had in the United States have been resolved, but my mind has not changed because, as people, we all have different cultures." In discussing such resolution, Participant 7 stressed the word "accept":

When I was a freshman I got into an altercation with my American roommate over the temperature of the room. I just had to accept that we are from different cultures. The situation was resolved, and I was able to get my own room. Now I can turn the temperature how I like it. I feel great; I feel good about the outcome. I can sleep better at night so in the morning I feel much more refreshed. I learned from that situation that there can be temporary solutions to problems for international students but we have to accept that we are just different from Americans.

Participant 9 acknowledged that she had a better understanding of the environment. She stated, 
I know the environment much better, including the buildings, the temperature, and the people. I know what to expect. I guess you could say that I fit in better socially because I have accepted the differences and learned to live with them.

The majority (seven; 77\%) of the participants expressed acknowledgment that they had accepted that differences in cultures will always exist. The seven participants all stated that, despite the cultural differences, they were able to resolve any conflicts that arose, and three $(33 \%)$ believed that they had a better understanding of the environment around them, which assisted with their social integration. The idea that people are just different and that cultural differences cannot be changed was espoused by $33 \%$ of the participants, who acknowledged that they were still able to adjust socially despite that mindset.

\section{DISCUSSION AND CONCLUSIONS}

The study of the role of emotional and cultural intelligence in the social integration of international students was significant because the number of international students has grown steadily over the past decade, and such students contribute significantly to the American economy. However, the challenges international students face also continues to expand and, although there is considerable existing research to identify these challenges, not many researchers have examined the reasons for the challenges (Chen, Hicks \& While, 2014; Sandhu \& Asrabadi, 1994; Wang et al., 2012).

The study findings revealed views that emotional and cultural intelligence played an important role in enabling international students to integrate socially into the private southern university that was the setting. The findings also revealed the many cultural differences and feelings experienced by international students during their collegiate years and the fact that they were better able to integrate socially when they had a better understanding of the American culture. In their research, Earley and Ang (2003), who developed the four factors of cultural intelligence model, and Goleman (1998), who identified the four elements essential to increasing one's emotional intelligence, asserted that strengthening these intelligences increases the chance of an individual being socially involved. The findings in the current study disclosed a similar outcome for social integration of international students. 
Findings regarding the influence of emotional and cultural intelligence on social integration reflect the importance of social programs being put in place by leaders of institutions of higher learning that have international students. The majority of the participants in the current study expressed a change in their social behavior; however, some also expressed discomfort with losing their identity in their decision to embrace the American culture. A consensus existed among the participants that, initially, the adjustment was lacking, but the available resources provided an opportunity for the international students to achieve social integration.

\section{IMPLICATIONS}

It has been more than 50 years since international students started coming to the United States to attend colleges, and the benefits are tremendous for all involved, including the students, the universities, and the American economy. Despite efforts on the part of administrators to provide better accommodations and resources for international students attending their universities, the growing social challenges faced by international students continue to be of concern. Evidence from previous research suggests that the challenges faced by international students are well documented, but not enough effort is being expended on finding solutions to the challenges.

Continued social challenges have had a negative effect on the academic and social performance of international students in American universities (Sherry et al., 2010). This is the first study to explore the role of emotional and cultural intelligence in understanding the social integration of international students. The research method allowed the participants of the study to provide understanding through their experiences, i.e., the cultural and emotional challenges experienced while socially integrating into the university. The findings of the study complement the existing literature supporting the concept that cultural and emotional factors play a role in social integration among individuals living in another country.

Reproducing the study with a larger sample of participants from varying universities could provide an opportunity for generalization of the study findings. The study findings point to available resources as a major consideration in students' adapting socially in American universities. The participants' stories all indicated that the available resources can significantly affect not just whether an individual is able to integrate socially, but also the length of time to achieve such integration. A future 
comparison study involving several students from all continents would determine if emotional and cultural intelligence has a bigger role based on the individual's region.

\section{REFERENCES}

Ahn, J., \& Ettner, L. (2013). Cultural intelligence (CQ) in MBA curricula. Multicultural Education \& Technology Journal, 7(1), 4-16.

Alsmadi, Y. M., \& Alsmadi, A. A. (2009). Detecting differential person functioning in emotional intelligence. Journal of Instructional Psychology, 36(4), 284 288.

Ang, S., Van Dyne, L., Koh, C., \& Ng, K. Y. (2004, August). The measure of cultural intelligence. Paper presented at the meeting of the Academy of Management, New Orleans, LA.

Ang, S., Van Dyne, L., Koh, C., Ng, K. Y., Templer, K. J., Tay, C., \& Chandrasekar, N. A. (2007). Cultural Intelligence: Its measurement and effects on cultural judgment and decision making, cultural adaptation, and task performance. Management and Organization Review, 3(3), 335-371. doi:10.1111/j.1740-8784.2007.00082.x

Ang, S., Van Dyne, L., \& Tan, M. L. (2011). Cultural intelligence. In R. J. Sternberg \& S. B. Kaufman (Eds.), Cambridge Handbook on Intelligence (pp. 582-602). New York, NY: Cambridge Press.

Arasaratnam, L. A., \& Doerfel, M. L. (2005). Intercultural communication competence: Identifying key components from multicultural perspectives. International Journal of Intercultural Relations, 29, 137-163.

Bazerman, M. (2014). The power of noticing: What the best leaders see. New York, NY: Simon \& Schuster.

Birknerová, Z. (2011). Social and emotional intelligence in school environment. Asian Social Science, 7(10), 241-248. doi:10.5539/ass.v7n10p241

Chaffey, L., Unsworth, C. A., \& Fossey, E. (2012). Relationship between intuition and emotional intelligence in occupational therapists in mental health practice. American Journal of Occupational Therapy, 66(1), 88-96.

Chen, Y., Hicks, A., \& While, A. (2014). Loneliness and social support of older people in China: a systematic literature review. Health and Social Care in the Community, 22(2), 113-123.

Coban, B., Karademir, T., Acak, M., \& Devecioglu, S. (2010). The emotional intelligence of students who are sitting a special-ability examination. Social Behavior \& Personality: An International Journal, 38(8), 1123 1134. doi:10.2224/sbp.2010.38.8.1123

Coover, G. E., \& Murphy, S. T. (2010). Study that examined the relationship between self-identify and academic persistence and achievement in a 
counter-stereotypical domain. Journal of Abnormal Psychology, 113, $217-$ 227.

Creswell, J. W. (2013). Qualitative inquiry and research design: Choosing among five approaches (3rd Ed). Thousand Oaks, CA: Sage.

Diao, A., \& Park, D. S. (2012). Culturally intelligent for satisfied workers in a multinational organization: Role of intercultural communication motivation. African Journal of Business Management, 6(24), 7296-7309.

Dusi, P., Messetti, G., \& Steinbach, M. (2014). Skills, attitudes, relational abilities \& reflexivity: Competences for a multicultural society. Procedia: Social and Behavioral Sciences, 112, 538-547. doi:10.1016/j.sbspro.2014.01.1200

Earley, P. C. (2002). Redefining interactions across cultures and organizations: Moving forward with cultural intelligence. Research in Organizational Behavior, 24, 271-299.

Earley, P. C., \& Ang, S. (2003). Cultural intelligence: Individual interactions across cultures. Stanford, CA: Stanford University Press.

Earley, P. C., Ang, S., and Tan, J.-S. (2006). CQ: Developing cultural intelligence at work. Stanford, CA: Stanford Business Books.

Englander, M. (2012). The interview: Data collection in descriptive phenomenological human scientific research. Journal of Phenomenological Psychology, 43, 13-35.

Engle, R., and K. A. Crowne. (2014). The impact of international experience on cultural intelligence: An application of contact theory in a structured shortterm program. Human Resource Development International. 17 (1), 30-46.

Finlay, L. (2013). Unfolding the phenomenological research process: Iterative stages of "seeing afresh." Journal of Humanistic Psychology, 53(2), 172201. doi: $10.1177 / 0022167812453877$

Franklin-Craft, A. (2010). An assessment of the intercultural competence of student affairs administrators (Doctoral dissertation). Available from ProQuest Dissertations and Theses database. (UMI No. 3435119)

Gallagher, S., \& Zahavi, D. (2012). The phenomenological mind (2nd ed.). New York, NY: Routledge.

Gawali, K. C. (2012). Relationship between emotional intelligence and positive affectivity among college teachers. Golden Research Thoughts, 1(7), 1-5.

Goleman, D. (1998). Working with emotional intelligence. New York, NY: Bantam.Grant, L., Kinman, G., \& Alexander, K. (2014). What's all this with emotion?

Developing emotional intelligence in social work students. Social Work Education, $33,874-889$.

Groves, K. S., \& Feyerherm, A. E. (2011). Leader cultural intelligence in context: Testing the moderating effects of team cultural diversity on leader and team performance. Group \& Organizational Management, 36(5), 535-566. doi: $10.1177 / 1059601111415664$ 
Gupta, B., Singh, D., Jandhyala, K., \& Bhatt, S. (2013). Self-monitoring, cultural training and prior international work experience as predictors of cultural intelligence: A study of Indian expatriates. Organizations and Markets in Emerging Economies, 4(1), 56-71.

Habib, L., Johannesen, M., \& Øgrim, L. (2014). Experiences and challenges of international students in technology-rich learning environments. Journal of Educational Technology \& Society, 17(2), 196-206.

Holinka, C. (2015). Stress, emotional intelligence, and life satisfaction in college students. College Student Journal, 49(2), 300-311.

Huff, K., Song, P., \& Gresch, E. (2014). Cultural intelligence, personality, and cross-cultural adjustment: A study of Expatriates in Japan. International Journal of Intercultural Relations, 38, 151-157. doi:10.1016/j.ijintrel.2013.08.005

Hughes, N.K. \& Schlosser, A. (2014). The effectiveness of nurture groups: a systematic review. Emotional and Behavioral Difficulties, 19(4), 386-409.

Husserl, E. (1970). The crisis of European sciences and transcendental phenomenology: An introduction to phenomenological philosophy. Evanston, IL: Northwestern University Press.

Immordino-Yang, M. H. (2009). Social neuroscience and its application to education. In S. Feifer \& G. Rattan (Eds.). The neuropsychology of emotional disorders (pp. 15-22). Middletown, MD: School Neuropsychology Press.

Institute of International Education. (November 14, 2014). Open Doors 2014: International student enrollment increased by 8 percent in 2014 , led by strong increase in students from China. Retrieved from http://www.iie.org/Who-We-Are/News-and-Events/Press-Center /PressReleases/2014-11-14-Open-Doors-International-Students\#.Vw_SSPkrK70

Jyoti, J., \& Kour, S. (2015), "Assessing the cultural intelligence and task performance equation: Mediating role of cultural adjustment", CrossCultural Management 22 (2), 236-258.

Kim, Y. J., \& Van Dyne, L. (2012). Cultural intelligence and international leadership potential: The importance of contact for members of the majority. Applied Psychology: An International Review, 61, 272-294.

Kushner, K. A. (2010). Indian international students in American higher education: An analysis of India's cultural and socioeconomic norms in light of the international student experience. Journal of the Indiana University Student Personnel, 43, 17-25.

Lam, C., \& O'Higgins, E. (2012). Enhancing employee outcomes. Leadership \&Organization Development Journal, 33(2), 149-174. doi:10.1108/01437731211203465

Li, G., Chen, W., \& Duanmu, J.-L. (2010). Determinants of international students' academic performance: A comparison between Chinese and other 
international students. Journal of Studies in International Education, 14(4), 389-405.

Lodico, M., Spaulding, D., \& Voegtle, K. (2010). Methods in educational research: From theory to practice (2nd Ed). San Francisco, CA: Jossey-Bass.

MacNab, B., Brislin, R., \& Worthley, R. (2012). Experiential cultural intelligence development: Context and individual attributes. International Journal of Human Resource Management, 23, 1320-1341.

Malik, A., Cooper-Thomas, H., \& Zikic, J. (2014). The neglected role of cultural intelligence in recent immigrant newcomers' socialization. International Journal of Cross Cultural Management, 14, 195-213. doi: $10.1177 / 1470595813507245$

May, A. Y. C., \& Carter, S. (2012). From "learning" to "employability": Informing successful teamwork through social and emotional competencies. Economics, Management and Financial Markets, 7(3), 11-30.

Merriam, S. (2009). Qualitative research: A guide to design and implementation. San Francisco, CA: Jossey-Bass.

Mohammad, F., Chai, L. T., Aun, L. K., \& Migin, M. W. (2014). Emotional intelligence and turnover intention. International Journal of Academic Research, 6(4), 211-220.

Moustakas, C. (1994). Phenomenological research methods. Thousand Oaks, CA: Sage.

Nadeem, S., \& Haider, A. (2014). The relationship between emotional intelligence (EI) and organizational citizenship behavior (OCB): The moderating role of Islamic work ethics (IWE). ASEAN Journal of Psychiatry, 16(1), 1-11.

Neophytou, L. (2013). Emotional intelligence and educational reform. Educational Review, 65(2), 140-154.

Ng, K. Y., \& Earley, C. P. (2006). Culture and intelligence: Old constructs, new frontiers. Group and Organization Management, 31, 4-19.

Nichols, T. M., Kotchick, B. A., McNamara-Barry, C., \& Hasking, D. G. (2010). Understanding the educational aspirations of African American adolescents: Child, family, and community factors. Journal of Black Psychology, 36(1), 25-48. doi:10.1177/0095798409344084

Niţă, M. A. (2014). From emotional to spiritual intelligence in public administration. Juridicial Current, 17(1), 165-181.

Patton, M. Q. (2002). Qualitative research and evaluation methods. Thousand Oaks, CA: Sage. Peterson, M. (2014). Interviewing international students to understand the process of expatriate acculturation. Marketing Education Review, 24(1), 59-62.

Petrides, K. V., \& Sevdalis, N. (2010). Emotional intelligence and nursing: Comment on Bulmer-Smith, Profetto-McGrath, and Cummings (2009). International Journal of Nursing Studies, 47, 526-528. 
Petrovic, D. (2011). How do teachers perceive their cultural intelligence? Procedia Social and Behavioral Sciences, 11, 276-280.

Pope, D., Roper, C., \& Qualter, P. (2012). The influence of emotional intelligence on academic progress and achievement in UK university students. Assessment \& Evaluation in Higher Education, 37(8), 907-918.

Priya, A., \& Panchanatham, N. N. (2014). Personality in relation to emotional intelligence among the professionals. International Journal of Management \& Innovation, 6(2), 1-13.

Ramsey, Jase R., Livia L. Barakat, and Amine Abi Aad, (2014), "Committment to the study of international business and cultural intelligence: A multi-level model", Journal of Teaching in International Business 25, 267-282.

Rienties, B., Beausaert, S., Grohnert, T., Niemantsverdriet, S., \& Kommers, P. (2012). Understanding Academic Performance of international students: The role of ethnicity, academic, and social integration. Higher Education, 63(6), 685-700.

Rienties, B., Héliot, Y., \& Jindal-Snape, D. (2013). Understanding social learning relations of international students in a large classroom using social network analysis. Higher Education, 66(4), 489-504. doi:10.1007/s10734-0139617-9

Riggio, R. E. (2010). Before emotional intelligence: Research on nonverbal, emotional, and social Competences. Industrial \& Organizational Psychology, 3(2), 178-182. doi:10.1111/j.1754-9434.2010. 01221.x

Rockstuhl, T., Hong, Y. Y., Ng, K. Y., Ang, S., \& Chiu, C. Y. (2010). The culturally intelligent brain: From detecting to bridging cultural differences. Neuroleadership Journal, 3, 22-36.

Rockstuhl, T., Seiler, S., Ang, S., Van Dyne, L., \& Annen, H. (2011). Beyond general intelligence (IQ) and emotional intelligence (EQ): The role of cultural intelligence (CQ) on cross-border leadership effectiveness in a globalized world. Journal of Social Issues, 67(4), 825-840.

Ronen, Simcha, \& Oded Shenkar, (2013), "Mapping world cultures: Cluster formation, sources and implications", Journal of International Business Studies 44, 867-897.

Roy, B., Sinha, R., \& Suman, S. (2013). Emotional intelligence and academic achievement motivation among adolescents: A relationship study. International Refereed Research Journal, 4(2) 126-130

Rumrill, P. D., Cook, B. G., \& Wiley, A. (Eds.). (2011). Research in special education: Designs, methods and applications (2nd ed.). Springfield, IL: Charles C. Thomas.

Salkind, N. J. (2008). Statistics for people who (think they) hate statistics (3rd ed.). Thousand Oaks, CA: Sage.

Salovey, P., \& Mayer, J. D. (1990). Emotional intelligence. Imagination, Cognition, and Personality, 9, 185-211. 
Sandhu, D. S., \& Asrabadi, B. R. (1994). Development of an acculturative stress scale for international students: Preliminary findings. Psychology Reports, $75,435-448$.

Sherry, M., Thomas, P., \& Chui, W. H. (2010). International students: A vulnerable student population. Higher Education, 60(1), 33-46.

Sparkman, L. A. (2009). Emotional intelligence as a non-traditional predictor of student retention and graduation. Retrieved from: http://gradworks.umi.com/33/26/3326728.html.

Stark, P. B., \& Freishtat, R. (2014). An evaluation of course evaluations. Science, 1, $1-26$.

Thomas, D. C. (2005). Domain and development of cultural intelligence: The importance of mindfulness. Group \& Organization Management, 31(1), 78-99.

Tufford, L., \& Newman, P. (2010). Bracketing in qualitative research. Qualitative Social Work, 11(1), 80-96. doi:10.1177/1473325010368316

Turner, D. W., III. (2010). Qualitative interview design: A practical guide for novice investigators. The Qualitative Report, 15, 754-760.

Van Dyne, L., Ang, S., Ng, K.-Y., Rockstuhl, T., Tan, M. L., \& Koh, C. (2012). Sub- dimensions of the four factor model of cultural intelligence: Expanding the conceptualization and measurement of cultural intelligence. Social and Personality Psychology Compass, 6(4), 295-313

Verma, P., \& Dash, P. (2014). Gender and emotional intelligence of collage going students. The International Journal of Indian Psychology, 1(4), 114-120.

Vigoda-Gadot, E., and Meisler, G. (2010). Emotions in management and the management of emotions: The impact of emotional intelligence and organizational politics on public sector employees. Public Administration Review, 70(1), 72-86.

Wagner, T. (2008). The global achievement gap. New York, NY: Basic Books.

Wakeman, C. (2009). Emotional intelligence: Towards a generic framework for the 21 st century. Educational Futures, 2(1), 40-56.

Wang, K. T., Puri, R., Slaney, R. B., Methikalam, B., \& Chadha, N. (2012). Cultural validity of perfectionism among Indian students: Examining personal and family aspects through a collectivistic perspective. Measurement and Evaluation in Counseling and Development, 45, 32-48. Retrieved from http://mec.sagepub.com/content/45/1/32

Wols, A.S., Cholte, R.H.J., \& Qualter, P. (2015) Prospective associations between loneliness and Emotional Intelligence. Journal of Adolescence, 39, 40-48.

Yang, Y., Yeh, H., \& Wong, W. (2010). The influence of social interaction on meaning construction in a virtual community. British Journal of Educational Technology, 41(2), 287-306.

Yin, R. K. (2009). Case study research: Design and methods (4th ed.). Thousand Oaks, CA: Sage. 
Yip, M. (2014). A win-win for international student mentor programming. Journal of College Admission, 224, 2-3.

Yu, B., Chen, X., Li, S., Liu, Y., Jacques-Tiura, A. J., \& Yan, H. (2014). Acculturative stress and influential factors among international students in China: A structural dynamic perspective. PLOS ONE, 9(4), 1-8. doi:10.1371/journal.pone.0096322

ROHAN THOMPSON, PhD, is an Assistant Professor of Management in the School of Business and Technology at Huston-Tillotson University. Her major research interests lie in the area of academic global leadership, emotional and cultural intelligence, and non-profit organizations. Email: rrthompson@htu.edu

Manuscript submitted: February 26, 2017

Manuscript revised: May 30, 2017 Accepted for publication: February 04, 2018 